\title{
Development of Resource-Driven Scheduling Model for Mass Housing Construction Projects
}

\author{
Ar. A. Cindrela Devi and K. Ananthanarayanan
}

\begin{abstract}
Resource continuity is a key issue for Mass housing construction projects which are highly repetitive in nature. Resources are therefore being deployed repeatedly for the similar or identical tasks. In order to eradicate delays in mobilizing resources from one location to other, an efficient resource schedule is required. Traditional scheduling tools like CPM, PERTare less effective in scheduling repetitive construction projects, as they consider resources as unlimited. Nevertheless, almost all the repetitive scheduling methods developed so far have been giving focus on continuous repetitive projects, whereas in this paper, the emphasis is on discrete (non-linear) repetitive projects. As a solution approach, a Resource Driven Scheduling Model (RDSM) is developed as a management supporting tool for selection of appropriate resource options for deployment and schedules the activities appropriately. The objective of the research is to find and validate a repetitive construction schedule which minimizes the project duration and/or project cost, and maximizes resource utilization while satisfying the resource constraints and to sequence the activities with appropriate resource assignment. A case study is delineated to validate the RDSM and to demonstrate its various capabilities like generating the resource driven schedule and sequencing the activities as per the resource availability.
\end{abstract}

Index Terms-Resource utilization, repetitive construction projects, optimization, resource scheduling.

\section{INTRODUCTION}

The efficacy of managing a construction project mainly depends on proper planning and scheduling of resources. The problem of scheduling and sequencing of the repetitive activities in the presence of uncertainty and the resource constraints is widespread in today's construction industry. The repetitiveness of these works is based on the activities involved, the relationships between the activities within a particular unit and the resource required to carry out the tasks. The other immense challenge is resource allocation for repetitive construction activities. Moreover, project activities do not always require a constant number of resources over their duration; a resource may not be needed for the entire duration of the project. The situation becomes more critical in the construction of repetitive projects that contain identical or similar units, such as floors in multistory buildings, houses in housing developments, pipeline and sewage projects, highway construction projects or other infrastructure projects Hence, the deployment of resources for the repetitive constructions needs to be stressed in order to minimize the

Manuscript received May 3, 2014; revised July 3, 2014

A. Cindrela Devi is with Davis Langdon and Seach Consulting India Pvt Ltd, Chennai, India (e-mail: cindreladevi@gmail.com).

K. Ananthanarayanan is with Buiding Technology \& Construction Management, Civil Engineering Department, Indian Institute of Technology, Madras, India (e-mail: kananth@iitm.ac.in). ripple effects (Chain reaction management problem). Consequently, resource management is a key task in planning for implementing a construction project. A Resource-Driven Scheduling Model, proposed in this paper, aims to address these issues related to resource constraints. A decision making team can apply this resource management tool to study different scenarios involving resources and develop a schedule that accurately portrays resource dynamics.

\section{RESEARCH BACKGROUND}

\section{A. Project Scheduling}

Traditional scheduling tools like Critical Path Method (CPM), Programme Evaluation and Review Technique (PERT) focus on the project duration and give little consideration for effective use of resources. However, the site managers and contractors are more concerned about the effective use of resources rather than critical paths or early completion of the project [1]. The main concern is that these techniques do not consider the availability of resources while calculating the completion time of the project. Moreover, these techniques produce large and complex schedules when applied in the repetitive activities and the complexity increases with the increase in repetition. Hence it is highly impractical for projects that give more importance to resources allotment like mass housing projects. Another limitation is its inability to maintain crew work continuity [2]. Therefore, for smooth movement of resources, an optimized schedule is needed for minimizing the idle time, thereby maximizing the resource utilization.

\section{B. Optimization}

Optimization involves in three categories. The first category, mathematical optimization model includes linear programming, mixed integer programming, branch and bound and dynamic programming [3]. The second category discussed as heuristics where the models are based on decision rules for assigning priority with regard to resource allocation among various activities. However, they cannot guarantee to find the optimal solution. The other category is the evolutionary computation techniques, such as genetic algorithms [4] and local search techniques, such as ant colony algorithm, particle swarm optimization, simulated annealing and tabu search. Evolutionary techniques were used to achieve optimization of resources allocation and leveling concurrently and produced shorter project duration and a better-leveled resource profile [5], [6].

\section{Repetitive Projects}

The repetitive project has lots of repetitive activities which involve repetition of a unit throughout the project. The key feature of this type of construction is that a number of highly 
specialized construction crews are often required to repeat the same task in a number of repetitive units moving from one unit to another as in production lines. If these resources (labour and equipment) are not properly allocated among all activities, the continuity of work will get affected. Hence the deployment of resources is significant [7]. By planning the resources with continuous deployment, idleness can be reduced and resource utilization can be maximized. Even if the resources deployed continuously, the job cannot be started because of the work in progress of the preceding activity. So the crew allotted for that particular activity is forced to wait till the space vacated by the crew allocated for the preceding activities [8]. This idle time turns to the excess of project cost. Hence it needs to be minimized to have the project in control. Here, the idleness is due to the varying production rates and the delay is because of the inspection, rework, etc. In order to reduce idleness and to maximize the learning curve effect, maintaining resource continuity is much essential.

\section{RESEARCH OBJECTIVES}

The main objective of this research is to develop a model for scheduling the construction activities that addresses the challenges outlined in the earlier section and they are listed below

- To develop and evaluate an optimal construction schedule for mass housing construction projects.

- To determine optimal project duration/cost with the constraint of limited resource availability.

- To maximize the utilization of resources by means resource allocation to each of the activities.

- To schedule and sequence the construction activities according to the resource availability

The scope of the study pertains to the limited supply of the labour resources and unlimited supply of material resources and capital is assumed. The study does not taken into account the site and layout related factors, which also affect scheduling.

\section{DeVelopment of Resource-Driven Scheduling MODEL}

\section{A. RDSM Overview}

The Resource-Driven Scheduling Model (RDSM) is developed for the non-linear discrete repetitive projects that deal with the development of algorithms for scheduling the resources and sequencing the construction activities. The development of this algorithm builds on the analysis of available resource and considers practical factors commonly encountered in repetitive construction.

In order to develop a construction schedule for repetitive projects minimizing the project duration and maximizing the resource utilization, the algorithm should satisfy the three main constraints: i) precedence logic ii) resource availability iii) continuous deployment of resources. It should also consider the impact of a number of practical factors namely, typical activities, crew availability period on site, utilization of crews, activity interruption, sequence of construction operations and learning curve.

\section{B. RDSM System Architecture}

Fig. 1 illustrates the overall framework used to develop the RDSM system architecture, consists of four modules. Microsoft project and excel are integrated in Visual Basic platform for running the entire RDSM software code within a single applicationprogram.

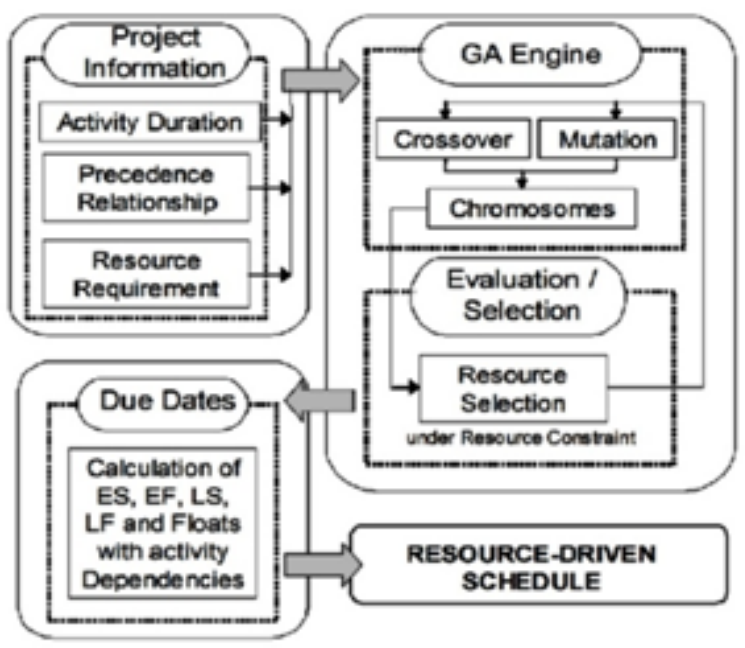

Fig. 1. RDSM system architecture.

The input module captures the project attribute and coordination elements. Elements optimization module represent the primary functional module comprising of the selection and evaluation of resource attributescapabilities using Genetic Algorithm. The scheduling module, shown in Fig. 2 is the main module contains project scheduling and sequencing information, integrates with other modules. This module computes the project duration based on the resource deployment sequence generated by optimization module. The output of the selection module along the project database and the executive management decision rules are the primary inputs to the second phase module. The main elements are the individual units, individual unit tasks and individual unit resource requirements.

To deal with this, the proposed RDSM is integrated with the optimization module which can be classified as two phases: the first phase is to select the appropriate resource/crew option to deploy the resources continuously in optimal way thereby maintaining crew work continuity and the second is to prepare the schedule considering the precedence logic and resource/crew availability constraints.

After the initialization of the optimization, the general project data as well as the specific activity data are passed on to the scheduling module. This module is designed to perform numerous scheduling calculations for repetitive activities. While performing scheduling, the module considers the basic constraints work availability and resource availability which are the main cause of idle time. The scheduling calculations are based on the resource availability and its deployment. The sequencing of the activities is based on the selection of the crew options. These calculations are performed by integrating data among various modules. The developed model uses Genetic Algorithms to optimally assign resources to repetitive activities, which is aimed to minimize the total project cost \& duration, idle cost \& time and to maximize resource 
utilization.

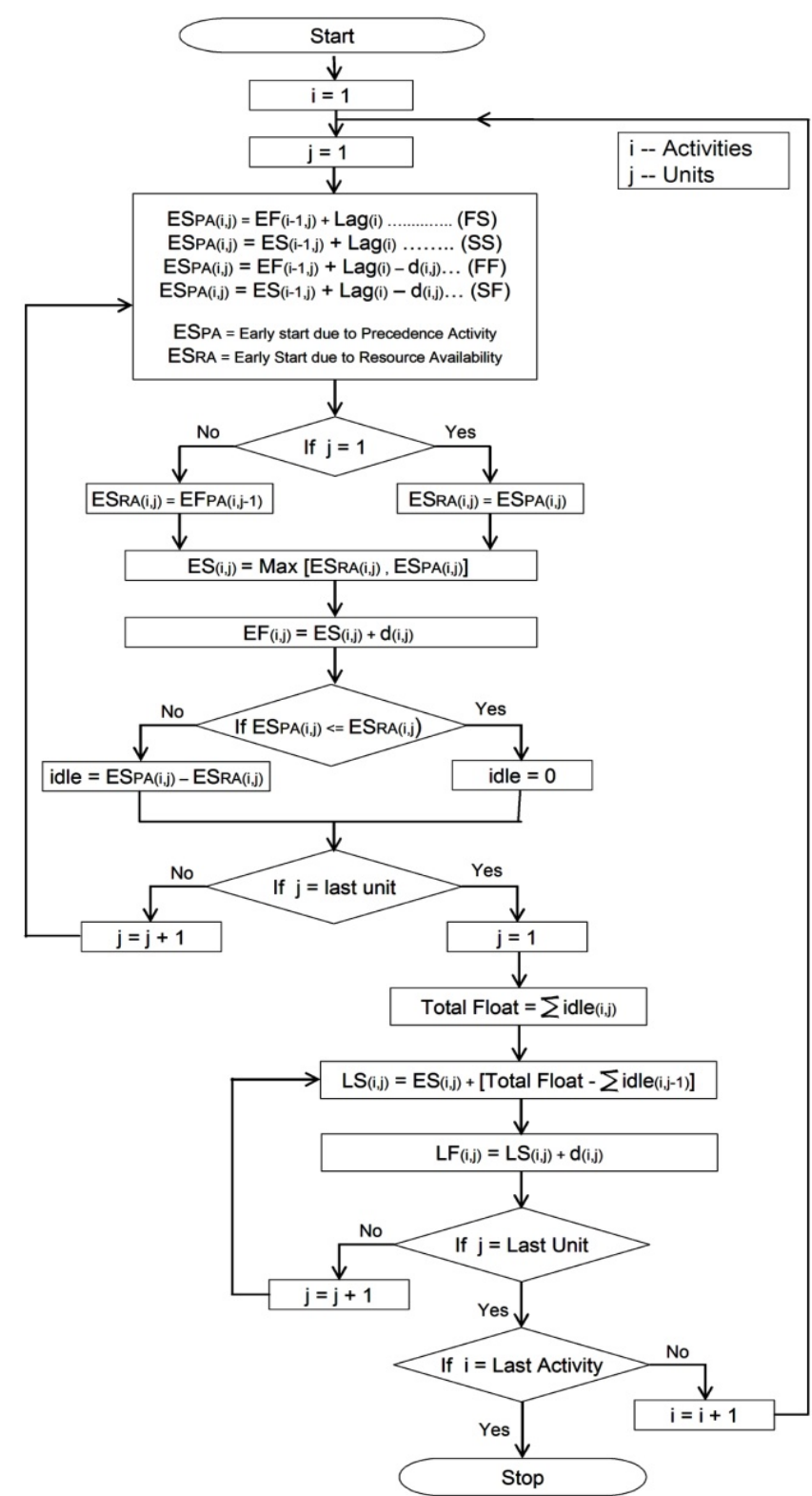

Fig. 2. Flowchart ofscheduling module.

\section{CASE Study}

\section{A. Description}

A Tsunami housing project at Nagapatinam, Tamil Nadu, India has beendelineated to illustrate the use of the developed Resource-Driven Scheduling Model and to demonstrate its capabilities. This project basically a calamity (Tsunami) relief project carrying out by the Government of Tamilnadu associated with other Non-Government Organizations. After the Tsunami hit in Tamilnadu, there is an immediate need for permanent accommodation for the people in the coastal area since the many of the coastal villages are totally washed away. Here one of the villages is demarcated which consists of 451 houses and construction of each house involves 18 activities. The resource (crew) availability is limited and therefore there is a need for allocating the available resources/crew to each of the activity as per the requirement. The management of the crew is found to be a major problem after regular discussion and meeting with the site and project managers. For the sake of making this paper concise, we have delineated the developed model with a set of fifteen units. The snapshot of the construction site is shown in the Fig. 3.

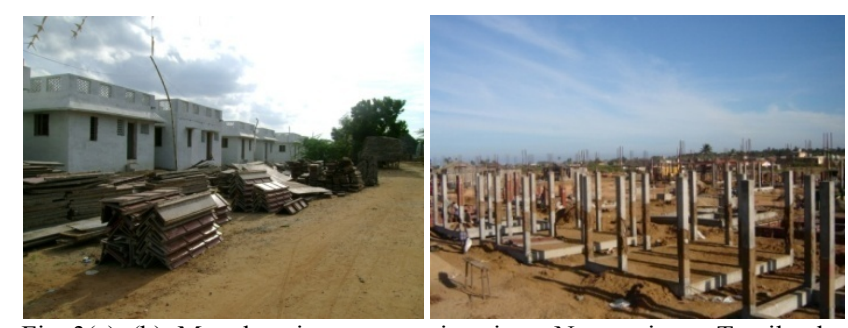

Fig. 3(a), (b). Mass housing construction site at Nagapatinam, Tamilnadu, India.

The priority of construction is given according to the location of the each unit's site for easy mobilization and sharing of resources. The houses were named in consistent with their position (matrix form) of the entire project site. Each activity is performed by a crew that progresses from the first unit to the last unit sequentially. The precedence logic is 'finish to start' and without lag time. The various crew options are provided with the labour composition and their productivity rate. The concerned input of the housing project is shown in Table I. The model can be executed even for a project having different types of construction units. It can also comprise of different crew compositions among the resource/crew options.

\section{B. Results and Discussions}

The RDSM can be utilized to determine the commencing time and completing time of each activity in each unit in the project by allocating the resource to each of the activities. This approach can be used to determine for any number of activities and units. Here, an example is worked out for 15 units in which each comprises of 18 activities and has three resource options in each of the activity.

- Variables: Allocation of resources / crew to each of the activity, sequence of the activity according to the resource availability

- Objective function : To minimize the project duration and maximizes the resource utilization

- Assumptions: The duration is deterministic. The availability of materials and equipments are unlimited. The activities will be completed in time as per the productivity mentioned. No splitting of activity is employed

The problem has been worked out to determine the resource scheduling and activity sequencing with the objective of minimum project duration, minimum project cost and maximum resource utilization respectively. It enables the construction planners to efficiently and effectively generate and select an optimal schedule and resource utilization plan that achieves the desired tradeoff among project objectives

Fig. 4 shows the overall detail about the resource used and the time taken for completing each activity as well the project. The detailed graph of resource/crew deployment and the activity timings can also be extracted from the schedule. It also gives a clear idea about the crew idle time and the job waiting time. The schedule reduces the ripple effect by the optimal resource plan which controls the resource movement. 
TABLE I: INPUT STATEMENT OF HOUSING CONSTRUCTION

\begin{tabular}{|c|c|c|c|c|c|c|c|c|c|c|}
\hline \multirow{2}{*}{ S.No } & \multirow{2}{*}{ Activity Name } & \multicolumn{3}{|c|}{$\begin{array}{c}\text { Resource Composition (No. of } \\
\text { labours) }\end{array}$} & \multicolumn{3}{|c|}{ Resource Option Duration (Days) } & \multicolumn{3}{|c|}{ Resource Option - Cost (INR) } \\
\hline & & Skilled & Semiskilled & Unskilled & 1 & 2 & 3 & 1 & 2 & 3 \\
\hline 1 & Setting Out \&Excavation & 1 & 6 & 5 & 1.00 & 1.50 & 1.25 & 1,130 & 1,130 & 1,200 \\
\hline 2 & Foundation & 2 & 8 & 5 & 1.00 & 1.50 & 1.25 & 2,350 & 2,125 & 2,550 \\
\hline 3 & Column Shoe (I) & 0 & 0 & 0 & 1.00 & 1.00 & 1.00 & 100 & 100 & 100 \\
\hline 4 & Grade Beam & 2 & 8 & 5 & 2.00 & 2.50 & 2.25 & 2,875 & 2,525 & 3,050 \\
\hline 5 & Column Shoe (II) & 0 & 0 & 0 & 1.00 & 1.00 & 1.00 & 90 & 90 & 90 \\
\hline 6 & Column & 2 & 8 & 5 & 2.00 & 2.50 & 2.25 & 1,100 & 1,000 & 1,200 \\
\hline 7 & Brickwork (I) & 6 & 12 & 6 & 5.00 & 5.50 & 5.25 & 2,150 & 1,950 & 2,300 \\
\hline 8 & Roof concreting & 4 & 15 & 6 & 4.00 & 4.50 & 4.25 & 5,400 & 3,850 & 5,625 \\
\hline 9 & Curing & 0 & 0 & 2 & 10.00 & 10.00 & 10.00 & 50 & 50 & 50 \\
\hline 10 & $\begin{array}{l}\text { Dummy Column and } \\
\text { decentering }\end{array}$ & 2 & 8 & 5 & 2.00 & 2.50 & 2.25 & 3,350 & 3,125 & 3,510 \\
\hline 11 & Brickwork (II) & 6 & 12 & 6 & 3.00 & 3.50 & 3.25 & 3,185 & 3,425 & 3,600 \\
\hline 12 & Carpentry & 2 & 2 & 1 & 2.00 & 2.50 & 2.25 & 2,400 & 2,350 & 2,625 \\
\hline 13 & Electrical Work & 2 & 2 & 1 & 1.00 & 1.50 & 1.25 & 350 & 400 & 440 \\
\hline 14 & Plastering & 12 & 6 & 3 & 7.00 & 7.50 & 7.25 & 4,400 & 3,050 & 4,500 \\
\hline 15 & Curing (II) & 0 & 0 & 2 & 1.00 & 1.00 & 1.00 & - & - & - \\
\hline 16 & Flooring & 2 & 4 & 4 & 2.00 & 2.50 & 2.25 & 1,125 & 1,025 & 1,250 \\
\hline 17 & Painting & 3 & 3 & 2 & 4.00 & 4.50 & 4.25 & 4,050 & 4,050 & 4,200 \\
\hline 18 & Finishing Touchup & 6 & 12 & 6 & 1.00 & 1.50 & 1.25 & 200 & 200 & 200 \\
\hline
\end{tabular}

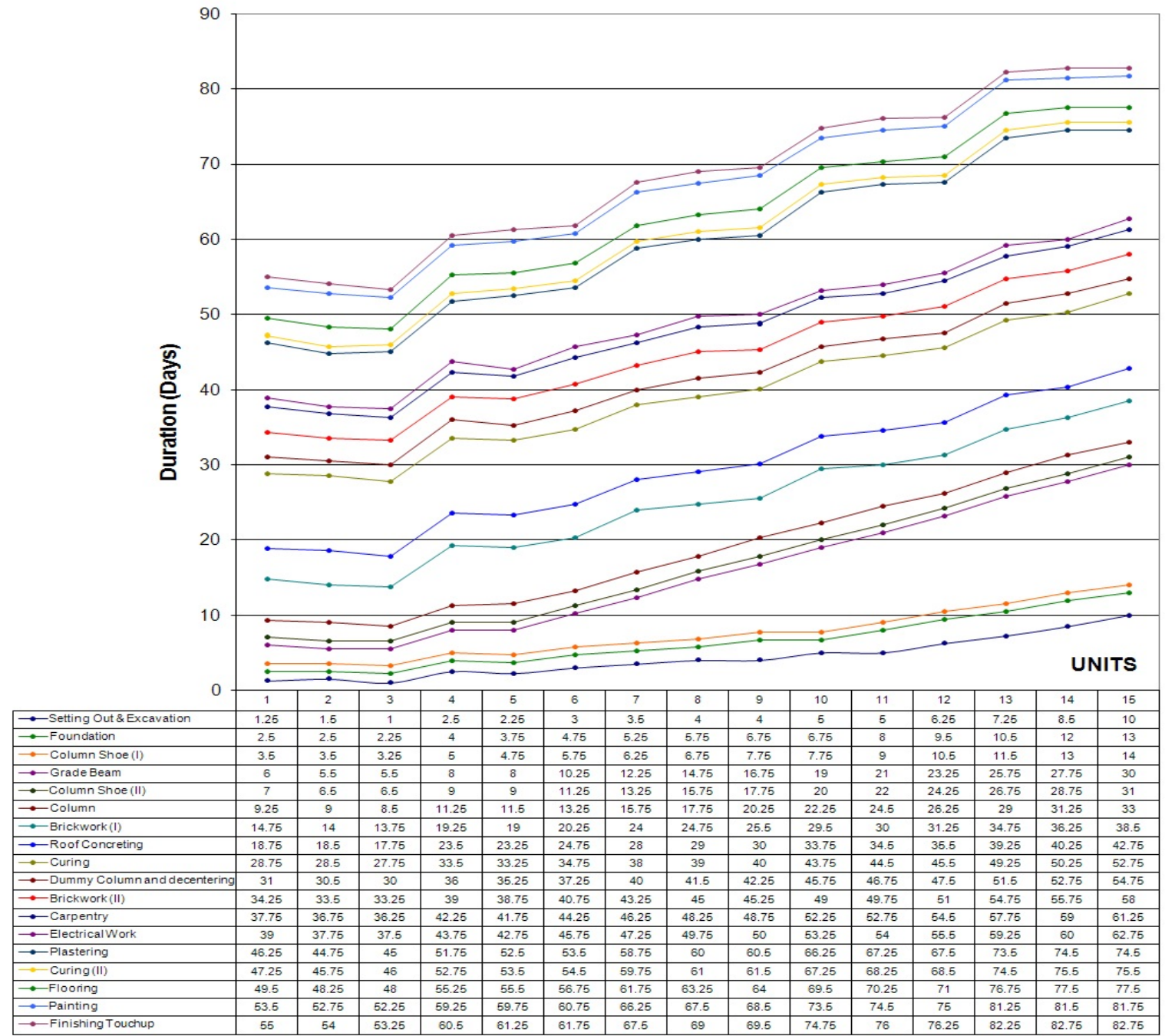

Fig. 4. Activity and Resource schedule of the housing construction for minimum project duration.

So the external resources can be mobilized or slow down some of the activities according to the budgeted cost of the project. The auto-generated schedule shows the project duration as 82.75 days. The varying duration in each of the unit denotes the varying productivity of crew options and their availability. The generated resource plan leads to the optimal sequence to execute the construction to achieve minimum project duration with maximum crew utilization. External resources can be mobilized for the activities grade beam, plastering to further lessen the project duration.

To analyze the construction project for various conditions, the model can be run for various objectives with certain 
relevant weight age.

The cash flow curves for the three above mentioned objectives are shown in Fig. 5. It is observed that the cash flow curves for the schedule for minimum project duration and that for maximum resource utilization are comparable. This is due to fact that both the schedules aim at ensuring resource-work continuity which is achieved through minimizing the idle time of resources. The schedule for the minimum project cost, despite ensuring overall minimum cost, suffers from longer project duration. This is because of the interrupted allocation of the resources.

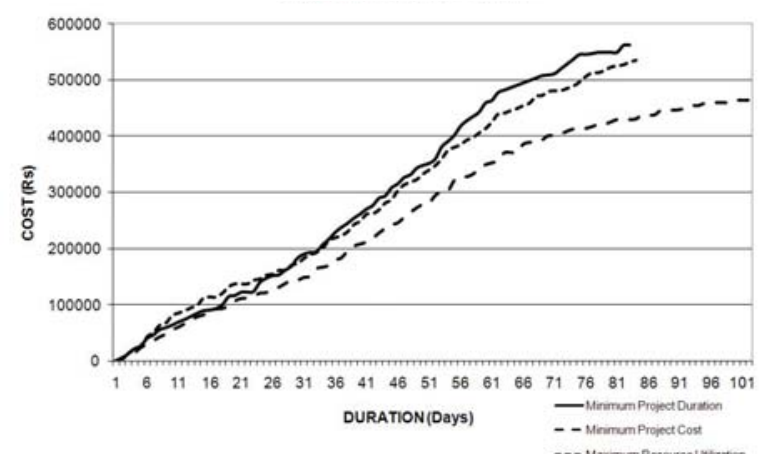

Fig. 5. Comparison of cumulative cost flow curves for the three objectives considered.

\section{SUMMARY AND CONCLUSION}

An automated model has been developed for optimizing resource utilization for repetitive construction projects. This model supports the planning and scheduling of repetitive construction projects with the resource constraints. It is based on the Genetic Algorithm, designed to identify appropriate selection of the resource option for each activity in the project that leads to the minimum project duration, minimum project cost or maximum resource utilization. The model incorporates a scheduling algorithm and cost $\mathrm{c}$ mputation.

The scheduling algorithm complies with job logic, resource availability and work continuity constraints and minimizes the idle time by continuous deployment of the resources.

The proposed model enables construction planners to generate and evaluate near optimal construction plans for

- Minimum project duration with the constraint of limited resource available.

- Maximize the utilization of resource by means resource allocation to each of the activities.

- schedule and sequence the construction activities according to the resource available

Each of these generated plans identifies, from a set of feasible alternatives, an optimal level of resource utilization for each activity in the project. To accomplish this, the model incorporates with various modules for accomplishing as a system. The new and unique capabilities of scheduling model prove useful to construction planners and are expected to advance existing planning and scheduling practices for repetitive construction projects.

The results of this analysis illustrates the new capabilities of the developed model in generating the optimal solutions for project Duration, Cost and Resource Utilization andthus, leads to facilitate the selection of the best overall plan for constructing the project

\section{ACKNOWLEDGMENT}

The authors gratefully acknowledge the Non-Government Organization, South Indian Federation of Fishermen Societies (SIFFS) for providing required information on Tsunami Housing Construction.

\section{REFERENCES}

[1] G. S. Birrell, "Construction planning- Beyond the critical path," Journal of Construction Engineering and Management, vol. 106, no. 3, pp. 389-407, Sep. 1980.

[2] R. M. Reda, "RPM: Repetitive project modeling," Journal of Construction Engineering and Management, vol. 116, no. 2, pp. 316-330, May 1990

[3] K. E. Rayes and O. Moselhi, "Resource-Driven scheduling of repetitive activities on construction projects," Journal of Construction Engineering and Management, ASCE, vol. 107, no. 2, pp. 18-27, Jun. 1998.

[4] K. E. Rayes and O. Moselhi, "Optimizing resource utilization for repetitive construction projects," Journal of Construction Engineering and Management, vol. 16, no. 4, pp. 433-446, Nov. 2001.

[5] D. E. Goldberg, "Genetic algorithm in search, optimization and machine learning," Addison- Wesley Reading, Mass, 1989, pp. 123-135.

[6] T. Hegazy, "Optimization of resource allocation and leveling using genetic algorithm," Journal of Construction Engineering and Management, ASCE, vol. 125, no. 3, pp. 167-175, Sep. 1999.

[7] K. Hyari and K. E. Rayes, "Optimal planning and scheduling for repetitive construction projects," Journal of Management in Engineering, vol. 22, no.1, pp. 11-19, Mar. 2006.

[8] A. D. Russell and W. C. M. Wong, "New generation of planning structures," Journal of Construction Engineering and Management, $A S C E$, vol. 119, no. 2, pp. 196-214, Feb. 1993.

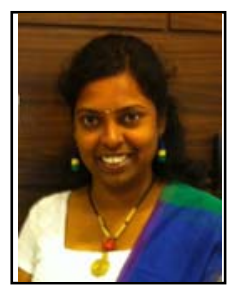

Ar. A. Cindrela Devi was born in 1984, Chennai, India. She was graduated in architecture at Madras University, India in 2005 and she finished her postgraduate study with master degree in science by research in building technology and construction management at Indian Institute of Technology, Madras India in 2008, she received her secured certificate in dispute resolution at Indian Institute of Arbitration and Mediation, Kochi, India in the year 2012.

She has seven years of work experience in the field of Planning and contracts in the construction industry. Her major field is budgeting and costing for the construction projects. Currently, works at Tata Housing Development Company, Chennai, India as regional coordinator. She has published few research papers and has participated in few international conferences

Ar. A. Cindrela Devi is a registered member in Council Of Architecture, India and member of International Association of Computer Science and Information Technology (IACSIT).

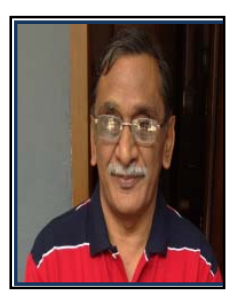

K. Ananthanarayanan was born in 1954, Kallidaikurichi Tamil Nadu, India, he was graduated with bachelor of engineering-civil engineering in 1976 at Madras University, India, he finished his postgraduate study with master of engineering-structural engineering in 1978 at Madras University, India and he received his secured doctor of Philosophy-construction management in 1996 at Indian Institute of Technology Madras, India.

He has got more than 35 years of service in the teaching and research institution. He has guided annumber of $\mathrm{PhD}$ and MS research projects. Currently he is working as a professor in the Department of Civil Engineering at Indian Institute of Technology, Madras, India. He has published more than 60 Journal and conference papers. He has also involved in number of research and consultancy projects.

Dr. Ananthanarayanan is a member in the Institution of Engineers (India), The Indian Road Congress, and Senior member of International Development Research Center (IEDRC), Member of International Association of Computer Science \& Information Technology ( IACSIT). 